\title{
National or population level interventions addressing the social determinants of mental health - an umbrella review
}

Neha Shah ${ }^{1 * \dagger}$, Ian F. Walker ${ }^{2+}$, Yannish Naik ${ }^{3}$ Selina Rajan ${ }^{5}$, Kate O'Hagan ${ }^{6}$, Michelle Black ${ }^{4}$, Christopher Cartwright ${ }^{7}$, Taavi Tillmann ${ }^{8}$, Nicola Pearce-Smith ${ }^{6}$ and Jude Stansfield ${ }^{9}$

\begin{abstract}
Background: Social circumstances in which people live and work impact the population's mental health. We aimed to synthesise evidence identifying effective interventions and policies that influence the social determinants of mental health at national or scaled population level. We searched five databases (Cochrane Library, Global Health, MEDLINE, EMBASE and PsycINFO) between Jan 1st 2000 and July 23rd 2019 to identify systematic reviews of population-level interventions or policies addressing a recognised social determinant of mental health and collected mental health outcomes. There were no restrictions on country, sub-population or age. A narrative overview of results is provided. Quality assessment was conducted using Assessment of Multiple Systematic Reviews (AMSTAR 2). This study was registered on PROSPERO (CRD42019140198).
\end{abstract}

Results: We identified 20 reviews for inclusion. Most reviews were of low or critically low quality. Primary studies were mostly observational and from higher income settings. Higher quality evidence indicates more generous welfare benefits may reduce socioeconomic inequalities in mental health outcomes. Lower quality evidence suggests unemployment insurance, warm housing interventions, neighbourhood renewal, paid parental leave, gender equality policies, community-based parenting programmes, and less restrictive migration policies are associated with improved mental health outcomes. Low quality evidence suggests restriction of access to lethal means and multi-component suicide prevention programmes are associated with reduced suicide risk.

Conclusion: This umbrella review has identified a small and overall low-quality evidence base for population level interventions addressing the social determinants of mental health. There are significant gaps in the evidence base for key policy areas, which limit ability of national policymakers to understand how to effectively improve population mental health.

Keywords: Mental health, Public health, Public mental health, Health policy, Social determinants, Intervention, Population health

\footnotetext{
* Correspondence: neha.shah@phe.gov.uk

Neha Shah and lan F. Walker are joint lead authors.

${ }^{1}$ City University London, Northampton Square, EC1V OHB, London, UK

Full list of author information is available at the end of the article
}

(c) The Author(s). 2021 Open Access This article is licensed under a Creative Commons Attribution 4.0 International License, which permits use, sharing, adaptation, distribution and reproduction in any medium or format, as long as you give appropriate credit to the original author(s) and the source, provide a link to the Creative Commons licence, and indicate if changes were made. The images or other third party material in this article are included in the article's Creative Commons licence, unless indicated otherwise in a credit line to the material. If material is not included in the article's Creative Commons licence and your intended use is not permitted by statutory regulation or exceeds the permitted use, you will need to obtain permission directly from the copyright holder. To view a copy of this licence, visit http://creativecommons.org/licenses/by/4.0/ The Creative Commons Public Domain Dedication waiver (http://creativecommons.org/publicdomain/zero/1.0/) applies to the data made available in this article, unless otherwise stated in a credit line to the data. 


\section{Introduction}

Recent policy priorities in global mental health have focused on closing the treatment gap: improving the proportion of individuals experiencing a mental health problem who are able to access effective psychiatric treatments locally [1, 2]. This is rightly a policy focus globally, but not alone in importance.

The current global mental health action plan [3] also prioritises the promotion and prevention of mental health. The Sustainable Development Goals (SDGs) commit countries to 'reduce by one third pre-mature mortality from non-communicable diseases through prevention and treatment and promote mental health and wellbeing' by 2030 [4]. The recent Lancet Commission on Global Mental Health and Sustainable Development [5] emphasised a lack of progress in most nations. The Commission challenged the international community to address this 'prevention gap' in mental health.

There is now good evidence that various social determinants are associated with poor mental health outcomes. Socioeconomic factors such as poverty $[6,7]$, (un) employment and poor working conditions [8-11] and macroeconomic changes such as recessions [12,13] are associated with mental health. Housing and homelessness [14-16] are also important factors, as are social capital and the availability of social support [17-20]. Other social determinants associated with mental health include crime [21], violence [22-24], education [25-27], social protection mechanisms such as welfare benefits $[28,29]$ and access to the natural environment (particularly in urban areas) [30, 31].

Many of these determinants were identified in a recent review of reviews [32] of the social determinants of mental health, which incorporated them into a conceptual model using the SDGs, identifying potential targets for intervention. Whilst the importance of intervention in these areas has been recognised, [33, 34] the effectiveness of national or population level policies addressing these social determinants to improve population mental health has not been systematically analysed [35]. Because of this lack of evidence, it is unclear what policies countries can implement to effectively address population mental health.

We undertook this umbrella review to identify the best available evidence for national or population level policies or interventions that improve population mental health and wellbeing by addressing the social determinants of mental health.

\section{Methods}

\section{Review question}

Umbrella reviews provide a transparent and rigorous approach, using systematic review methodology, to locate, appraise and summarise the highest quality evidence from published systematic reviews on a topic [36]. The protocol for this review is registered on PROSPERO (CRD42019140198). Our research question was: What national or population-level interventions or policies that address the social determinants of mental health have evidence of an effect on mental health and wellbeing?

\section{Search strategy}

We systematically searched several databases (Cochrane Library (Wiley), Global Health (Ovid), MEDLINE (Ovid), EMBASE (Ovid) and PsycINFO (Ovid) using search strategies developed by a Senior Information Scientist (see online Additional file 1 for Medline strategy). We were only interested in contemporary findings that would be applicable for the current context so restricted our search from January 1st 2000 to July 23rd 2019. We also undertook citation searches by checking the references of included studies to identify any further reviews. Grey literature sources were not searched.

Reviews, scoping reviews, systematic reviews and metaanalyses that were published in peer-reviewed journals and met the Database of Abstracts and Reviews of Effects (DARE) [37] criteria for systematic reviews were included. Reviews including before-and-after studies were included. Only reviews in English were included as we had no other technical language skills in the review team.

Reviews were included if they reported national/population level policies or initiatives that had been evaluated at that scale (larger regions/provinces were included if the population was over a million). We placed no restrictions on age, country or sub-population. All sectors that incorporated a social determinant of mental health as recognised by World Health Organisation (WHO) [38] were included (see appendix for search strategy). Reviews needed to report evidence of outcome in respect to positive mental health, wellbeing, reduction in symptoms of mental ill-health, reduction in completed or attempted suicides or prevention of mental health problems. Outcomes were recorded using self-reported wellbeing, screening instruments and diagnostic interviews. Reviews were excluded if they did not include interventions delivered at national/population scale or did not extract mental health outcomes.

\section{Data collection}

EndNote reference management software [39] was used to store and perform an initial screen of the references. After duplicates were removed, pairs of researchers independently screened titles and abstracts against the inclusion criteria. Disagreements were resolved through discussion between pairs with unresolved disagreements arbitrated by a third researcher. 
A data extraction form (see additional file 3) was adapted from Naik et al. [12]. Data were double extracted by pairs of reviewers and then checked and arbitrated as in the first stage of screening. Inclusion criteria were based upon the scope and approach of the review. Some reviews included primary studies that were local level and some that were national level. We included these reviews but extracted only the relevant findings from the national/population level studies.

To undertake a quality assessment of each included review we used the Assessment of Multiple Systematic Reviews (AMSTAR 2 - see additional file 2) [40]. Although designed for reviews of healthcare interventions the AMSTAR 2 tool has been used in similar public health umbrella reviews [12, 32]. Only summary findings for mental health outcomes were extracted. All shortlisted reviews were included even if they were assessed as low or critically low quality, with acknowledgement made within the narrative of the need for caution when interpreting these results.

\section{Data synthesis}

Due to the heterogeneity of included studies in terms of methods, outcome measures, topic areas and contexts a meta-analysis was not planned or undertaken. A narrative overview is provided, grouping reviews into topic areas.

\section{Results}

After removing duplicates, 1218 studies were identified for initial screening. This identified 29 reviews for full text screening, of which 14 systematic reviews met the inclusion criteria. A further 6 reviews were identified from citation searches giving a total of 20 reviews included in this umbrella review (Fig. 1) (see additional files 4 and 5).

The reviews comprised a range of methodologies including meta-analyses and narrative reviews. The majority of reviews focused on high- or upper middle-income countries, and much of the underlying evidence base was made up of observational studies including cohort studies and cross-sectional studies rather than experimental intervention designs. There was some limited use of modelling studies.

Overall, the AMSTAR 2 assessment of quality indicated most reviews were of low or critically low quality, with only four reviews of a high or moderate quality. Common weaknesses included a lack of consideration of quality or bias, an unstructured discussion of these issues, and a range of different structured tools to appraise retrieved studies. Reviews were grouped according to five key domains from a conceptual framework of social determinants of mental health which aligns with the UN SDGs, and thus is relevant to an intent to align intervention evidence with national policy [32] (Table 1).

\section{Findings of included studies}

\section{Demographic determinants}

We found four reviews which addressed gender policy interventions and their impact on mental health (one of which focused on welfare but looked at gender equity), all of which were of critically low quality.

Length of maternity leave and whether the leave was paid or not was examined by three reviews [41] [42] [43], and included studies of either cross-sectional or longitudinal design. The majority of included studies were from the USA where there was no statutory paid leave; others were from Norway, Lebanon, Canada, Australia where there is paid leave. All three reviews concluded that taking longer and paid leave was associated with better maternal mental health outcomes. Two reviews $[42,43]$ reported positive benefits from 8 to 12 weeks of paid leave, with another review reporting benefits beyond 12 weeks of maternity leave [43]. All reported greater benefits to mental health or wellbeing with longer leave. The majority of studies assessed results at the individual level, and Aitken et al. [41] reported that no clear conclusion can be made from studies at the population level. There was some evidence to indicate that women experienced improved mental health outcomes when they received extra social support but worse mental health outcomes when their partner did not take any leave.

Borrell et al. [42] found evidence to support the association of policies related to violence against women, economic security, and family planning with better mental health in studies using data from Europe and USA [42]. US states where women had greater reproductive rights reported lower mental health problems at population level [44]. Another review concluded that gender inclusive welfare states (family focused benefits and labour market support for women) improve mental health outcomes in women but don't necessarily reduce socio-economic inequalities [45]. Dual-earner models, typical of Nordic countries, where both partners contribute to wage earning and caring responsibilities report better mental health outcomes for women. Conversely, market-oriented models which allow market forces to dominate how gender relations are shaped, leaving individuals to find private solutions based on their market resources and family support (typical in the UK) were associated with worse mental health outcomes for women [32, 45]. Dual-earner models appear to support women's employment while facilitating work life balance with more equitable sharing of domestic work, leading to better health outcomes.

\section{Economic determinants}

Seven reviews of mixed quality (three high and four critically low) looked at economic interventions. 


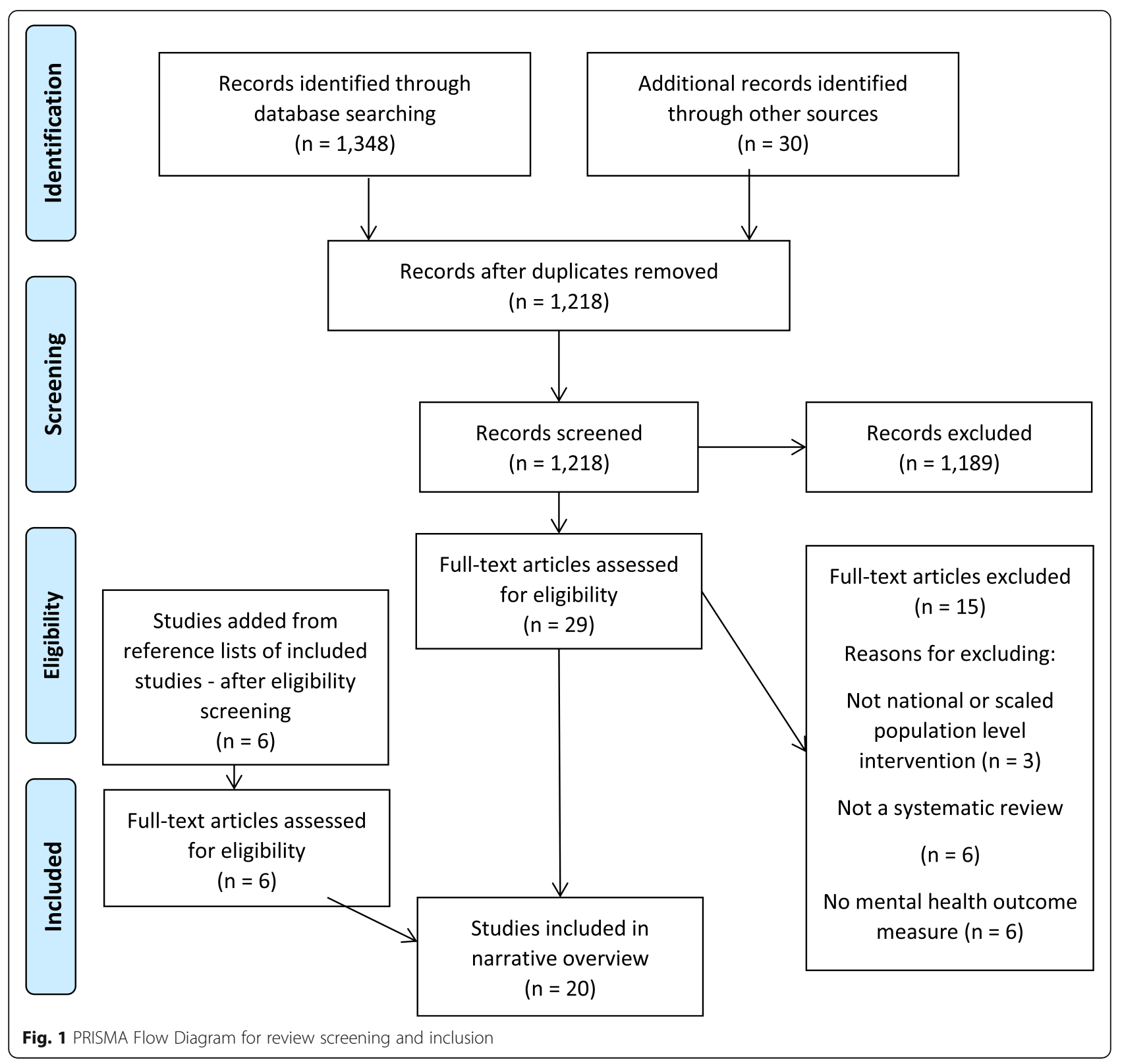

Two high quality reviews looked at conditional benefits such as tax credits and parental benefits tied to employment as examples of welfare to work policies [46, 47]; and concluded there was no effect of these policies on mental health outcomes. A meta-analysis looking at any type of 'welfare to work' interventions for lone parents [46] found an initial decline in parental mental health and no change in child mental health with subsequent improvements over time, up to six years following intervention implementation. However, the size of the effect was minimal suggesting this is of questionable importance. They also reported small initial increases in employment and income following the intervention, which disappeared over longer term. As such, mental health impacts did not appear to align with changes in employment and income.

Lucas et al. [48] in a high quality review examined the impact of welfare policies, such as direct cash payments and positive taxation schemes, aimed at socioeconomically disadvantaged families. They reviewed randomised controlled trial (RCT) evidence only and concluded there was no consistent evidence of effect on child mental health or emotional state measured at the individual level [48]. However, policies that are implemented may differ to those that are proposed and the authors concluded that the low monetary value and restrictive conditions placed on receiving such benefits within the included studies could have limited their effectiveness, 
Table 1 Overview of included study category and AMSTAR grading

\begin{tabular}{|c|c|c|c|c|c|}
\hline \multirow{2}{*}{$\begin{array}{l}\text { Conceptual } \\
\text { domain as per } \\
\text { Lund et al [32] }\end{array}$} & \multirow{2}{*}{$\begin{array}{l}\text { Relevant social determinant search } \\
\text { terms used }\end{array}$} & \multicolumn{4}{|c|}{ Amstar 2 Score for reviews (topic of focus) } \\
\hline & & High & Moderate & Low & Critically low \\
\hline Demographic & Stigma, prejudice & & & & 3 (gender equity) \\
\hline Economic & $\begin{array}{l}\text { Employment, income inequality economic } \\
\text { development }\end{array}$ & 3 (welfare) & & & $\begin{array}{l}4 \text { (unemployment } \\
\text { insurance or benefits) }\end{array}$ \\
\hline Neighbourhood & $\begin{array}{l}\text { Housing, violence, crime, community, } \\
\text { neighbourhood, volunteer }\end{array}$ & & 1 (housing intervention) & & 1 (housing provision) \\
\hline Environmental & $\begin{array}{l}\text { Conflict, environments, pollution, green/ } \\
\text { blue spaces, flooding }\end{array}$ & & & 1 (migration policy) & \\
\hline Social/Cultural & $\begin{array}{l}\text { Perinatal, parenting, school/education, } \\
\text { internet, nutrition, sleep, physical activity, } \\
\text { lifestyle, drugs, alcohol, social isolation, arts } \\
\text { culture, }\end{array}$ & & & & $\begin{array}{l}6 \text { (education and } \\
\text { awareness, screening, and } \\
\text { restricting means to } \\
\text { prevent suicide) } \\
1 \text { (parenting) }\end{array}$ \\
\hline
\end{tabular}

proposing that this may have been mediated by increased parental stress.

Two critically low quality reviews $[49,50]$ looked at effects of unemployment insurance (UI) internationally and concluded that more generous UI is associated with better mental health amongst both the unemployed and the employed. O'Campo et al. [50] in a realist review, report that the unemployed do not achieve the same levels of wellbeing as the employed. There was also evidence to indicate that generous UI was associated with reemployment being delayed until towards the end of the benefit period and thus may have negative consequences of disincentivising job-seeking or delaying employment which ultimately would be more beneficial to mental health. The impact of UI on self-rated health was lower in Germany than the US which authors speculated to be due to the receipt of support through other welfare programmes. Regional variations were also found in Spanish youth receiving UI, with both negative and positive mental health impacts. Authors proposed that stigma may account for negative impacts [51]..

McAllister et al. [45], in a review of critically low quality but using studies primarily appraised as high quality and with large samples, found consistent evidence that more generous welfare benefits were associated with reduced socioeconomic inequalities in mental health outcomes. The review also found evidence to the contrary, identifying associations between austerity measures and worse mental health across lower socioeconomic groups and increased suicide rates.

One review of critically low quality assessed the impact of privatisation of public sector utilities [52]. Only three studies were found, which looked at data from the UK and Portugal, and are now 20-30 years old. All three studies suggested detrimental impacts of privatisation on mental health of workers. Authors concluded this was due to job insecurity.

\section{Neighbourhood determinants}

One critically low quality review looked at the provision of mixed income housing (publicly subsidised rental housing development, with deliberate mixing of income groups) and tenant-based rental assistance programmes (subsidised housing for poorer families to live in more affluent neighbourhoods) [53]. Analysis of tenant-based rental assistance programmes suggests an overall $8 \%$ median reduction of symptoms of depression and anxiety by the head of household (range 6.5\% - 9.5\% reduction) based on two studies. The authors concluded that there were too few studies to draw a firm conclusion.

Another review of moderate quality focused on housing interventions [54]. It found evidence of improvements in mental health associated with warmth interventions; some limited and low-quality evidence of improvements in mental health associated with refitting and rehousing interventions; and inconsistent mental health impacts of neighbourhood renewal. McAllister et al. [45] also found evidence that neighbourhood renewal in deprived areas is associated with improved mental wellbeing in women and that area-based initiatives more generally can prevent or reduce social inequalities in mental health.

\section{Environmental determinants}

One review of low quality looked at entry and integration policies for migrants to high income countries [55]. Policies were categorised by generosity: whether migrants' access to health-promoting resources and opportunities was increased (generous) or limited (restrictive) by the policy. Meta-analysis of policies at 'entry' stage suggested that more restrictive entry policies, for example reduced mobility in detainment and use of temporary rather than permanent visas, were associated with an increase in scores for measures of psychological distress, depression, anxiety, or post-traumatic stress 
disorder [Standardised Mean Difference 0.44 (95\% CI 0.13 to 0.75$)$ ]. Meta-analysis suggested that more restrictive policies in the integration phase, such as burden of proof for eligibility, cost and long waiting times to access welfare support were associated with increased risk of poor mental health for migrants [OR 1.58 (95\%CI 1.03 to 2.42$)$ ]. In both cases, risk of bias among the included studies and substantial heterogeneity among the reported results led the authors to conclude with only a low level of certainty. The impacts of integration policies on migrant mental health varied according to the type of policy. The greatest mental health impacts were identified in contexts where migrants are seen as sociopolitically separate from their host society and access to welfare support is dependent on labour market participation (exclusionist) [56]. A protective documentation policy, allowing easier and longer-term legal rights to remain in the country was shown to be beneficial for mental health of undocumented migrants in robust and weak studies alike.

\section{Social/cultural determinants}

Five reviews of critically low quality looked at national level suicide prevention programmes and included interventions to improve education and awareness, implement screening for those at risk and restrict access to means [57-61].

\section{Restriction to means}

Gunnell et al. [57] concluded that following national bans of highly hazardous pesticides in countries such as Sri Lanka, South Korea and Bangladesh, where this was a commonly used method, pesticide suicides fell by between 24 and $40 \%$ and overall suicides by 8 to $24 \%$ compared to expected rates. Use of restrictive measures rather than bans did not always result in reduced deaths by suicide.

Zalsman et al. [61] found good evidence to support packaging of analgesics, erection of barriers at jump sites; detoxification of gas in catalytic converters in cars; restricting prescription and sales of barbiturates; reducing concentration of caffeine tablets; restricting pesticide availability where this is a prevalent risk factor for reducing suicides.

There were lower rates of suicide when restricting detoxifying domestic gas (19-33\% in UK and Switzerland), when restricting access to barbiturates (23\% in Australia); and mixed effects related to restricting gun access across a range of countries, with greater impact in high risk populations. Mann et al. [60] reviewed ecological studies suggesting that restricting access to guns was associated with $1.5-9.5 \%$ lower suicide rates in the US.

\section{Awareness and educational campaigns}

Torok et al. [58] and Zalsman et al. [61] found little evidence to support the use of mass media campaigns as a standalone approach to prevent suicide; however Torok et al. found positive results from studies that looked at mass media campaigns as part of a multi-component approach to suicide prevention. Three multicomponent studies reported reductions in attempted suicide of between 17 and 61\%, with one other study reporting reductions in actual suicide deaths.

Zalsman et al. [61] report that RCTs show reduced suicide attempts and ideation following school-based mental health and suicide awareness programmes, with or without combined mental health screening.

Mann et al. [60], reviewed the effects of components of suicide prevention strategies, and found that education of primary care physicians was associated with 2273\% lower annual suicide rates (using cohort data from Sweden, Hungary and Japan). Gatekeeper education is associated with $33-40 \%$ lower suicide rates in armed forces populations.

Zechmeister et al. [59] simulated cost effectiveness of scaling up two types of interventions (general awareness and preschool education). They estimated a fall in suicide rates of $57 \%$ following general education and $60 \%$ following peer support programmes, concluding that both were cost effective: one suicide could be prevented for every 2 dollars on general education and every 4 dollars spent on peer education. Lynch [62] used the 'Perry Pre-School study', together with three other similar studies, to develop an economic model and concluded that providing these programmes to just $20 \%$ of all 3 and 4 year olds living in poverty in the US could lead to return benefits of the value of between 4 and 9 dollars for every dollar spent on the intervention.

\section{Screening}

Zalsman et al. [61] concluded that there is insufficient evidence of the benefits of suicide screening in primary care populations for reducing risk of suicide, even when targeted in high-risk populations.

Kato et al., [63] in a review of critically low quality, looked at population level family interventions to improve mental health; with a focus on community based parenting programmes. Low quality studies were included and there was no formal quality appraisal. Childrens' and families' mental health improved, prevalence of child maltreatment reportedly decreased with positive results on behaviour and mental health problems of children and parental confidence.

\section{Discussion}

In this literature review, we found a broad, but generally low quality evidence base for interventions that address 
social determinants of mental health at the national or population level. Review level evidence was found across demographic, economic, neighbourhood, environmental, and social/cultural domains of social determinants of mental health as set out by Lund et al. [32], however the majority of the literature was focused in areas of economic intervention and suicide prevention. High level findings are outlined in Table 2. In Fig. 2, an overview of mechanistic pathways for the impact of national/population level interventions addressing social determinants of mental health has been synthesized from the intervention mechanisms proposed (although not necessarily tested) by authors of the included systematic reviews. The majority of pathways involve altering psychological stress experienced through exposure to social determinant risk factors for poor mental health, in particular financial/employment security and belonging to society.

\section{Key findings}

There are very few high quality reviews on the impacts of tackling the social determinants on mental health outcomes [35]. The majority of the reviews we included were rated to be of critically low quality. Most reviews included only a small number of studies with mental health outcomes. The majority of evidence from the primary studies was from higher income settings and may not be translatable elsewhere. Whilst some reviews were able to include RCTs, many were reliant on quasiexperimental designs with or without controls (including natural experiments), or used data from cohort and cross sectional studies including interrupted time series analyses and ecological studies.

There are several specific findings from this umbrella review.

First, we found high quality evidence to suggest that more generous welfare benefits may reduce socioeconomic inequalities in mental health outcomes, with evidence to the contrary, showing that austerity measures are likely to have detrimental impacts on mental health.

Second, a wide range of lower quality evidence suggests that social policies were associated with improved mental health outcomes. These included more generous unemployment insurance (which benefits both the employed and unemployed), warmth focused housing interventions, neighbourhood renewal, paid parental leave, gender equality policies, community based parenting programmes, and less restrictive migration policies. Restriction of access to lethal means and multilevel awareness and education programmes were associated with reduced suicide risk.

Third, there was high quality evidence that found no evidence of effect of conditional welfare-to work benefits on adult mental health outcomes. This may be because of the stress induced by the conditions attached to qualify for support or the benefits themselves being too small or restricted to improve material or psychological conditions of poverty. There was also no evidence of effect on child mental health outcomes.

Despite using several search terms, we found very little evidence on social, cultural and community based interventions, delivered at population level and their impact on mental health apart from those linked to suicide prevention. It is possible that these interventions, whilst widely used are under-evaluated or not evaluated specifically for mental health outcomes at a population level.

\section{Our findings in the context of the literature}

We address a critical gap in the literature, by examining the systematic review evidence base around the impacts of gender equality policies on women's mental health. This review found that evidence in this area was concentrated in high income countries, with little evidence found outside of US and Europe.

The findings of this review are in keeping with the WHO recommendations on national level action on social determinants of health $[64,65]$ which include targeting families of people with mental disorders in poverty alleviation programmes and social welfare for the unemployed. Lund et al. [28] discuss the association between poverty and mental disorders and that employment is protective of mental health. It is therefore unsurprising to find support for national welfare policy as an effective intervention for mental health; alongside indirect effects of unemployment insurance on the employed, likely through increased sense of security. This review also highlights need for more research and consideration of the conditionality, stigma and context of benefits and how these impact on effectiveness of interventions in these areas.

In the current context of the COVID-19 pandemic as well as numerous current natural disasters, violence and conflict, many linked to climate change, the need for national level intervention to address environmental determinants of mental health is clear, and the gap in literature on this specific domain is concerning.

We found little evidence for interventions in the neighbourhood domain, with warmth related housing interventions showing some promise. This is at odds with international policy recommendations for action to promote access to employment, health care, housing, and education to improve mental health outcomes [32, 64, 65]. This disparity may be due to the focus of our search being national/population level interventions, and thus not capturing relevant literature on neighbourhood and community-level interventions that may be delivered at scale. Addressing the factors associated with successful implementation and scale-up of evidence-based interventions, applying principles of implementation science 
Table 2 Overview of intervention effects and pathways

\begin{tabular}{|c|c|c|c|c|}
\hline Domain & Intervention & $\begin{array}{l}\text { Mechanistic pathway (as stated in } \\
\text { review) }\end{array}$ & $\begin{array}{l}\text { Overall evidence on MH } \\
\text { outcomes (positive effect, } \\
\text { negative effect, no effect, } \\
\text { inconclusive, mixed effect, } \\
\text { suggestive but inconclusive, } \\
\text { insufficient evidence) }\end{array}$ & $\begin{array}{l}\text { Strength of } \\
\text { Evidence: } \\
\text { AMSTAR } 2 \\
\text { grading } \\
\text { (number of } \\
\text { reviews) }\end{array}$ \\
\hline \multirow[t]{2}{*}{ Demographic } & Paid maternity leave & $\begin{array}{l}\text { Reduced stress associated with } \\
\text { transition and adapting to multiple } \\
\text { roles, new identities, financial strain. }\end{array}$ & positive & critically low (3) \\
\hline & $\begin{array}{l}\text { Gender equity policies e.g. } \\
\text { reproductive rights/ family } \\
\text { planning, policies related to } \\
\text { violence against women, family } \\
\text { supportive employment }\end{array}$ & $\begin{array}{l}\text { Reduction in stress, discrimination, } \\
\text { violence, financial difficulties, poverty, } \\
\text { double burden of work and caring/ } \\
\text { household tasks, or time pressure }\end{array}$ & positive & critically low (2) \\
\hline \multirow[t]{6}{*}{ Economic } & Generous welfare benefits & $\begin{array}{l}\text { Welfare state interventions alleviate } \\
\text { financial pressures on women } \\
\text { particularly, reducing gender } \\
\text { inequalities in mental health } \\
\text { outcomes }\end{array}$ & positive & critically low (1) \\
\hline & Austerity & $\begin{array}{l}\text { Reduced social spending limits } \\
\text { potential to alleviate psychosocial } \\
\text { stress related to health and social } \\
\text { care, employment, housing and } \\
\text { family needs for those seeking to } \\
\text { access state social support }\end{array}$ & negative & critically low (1) \\
\hline & Benefits for families in poverty & $\begin{array}{l}\text { Parental psychosocial stress as the } \\
\text { link between low income and child } \\
\text { mental health outcomes }\end{array}$ & no evidence of effect & high (1) \\
\hline & Welfare to work & $\begin{array}{l}\text { Increase in relative income position } \\
\text { reduces psychological stress. Also } \\
\text { combined consumption and status } \\
\text { effects, where income effects on } \\
\text { health are mediated by material } \\
\text { conditions and in turn social } \\
\text { exclusion, and thereby through both } \\
\text { physical and psychological } \\
\text { mechanisms. Parental stress in turn } \\
\text { impacts on child mental health. }\end{array}$ & no evidence of effect & high (2) \\
\hline & Unemployment insurance & $\begin{array}{l}\text { Generous UI increases financial } \\
\text { security which increases } \\
\text { psychological wellbeing. Effects on } \\
\text { employed are through reducing job } \\
\text { insecurity as a chronic psychosocial } \\
\text { stressor. Potential negative } \\
\text { mechanisms through disincentive to } \\
\text { work, stigma. }\end{array}$ & positive & critically low (2) \\
\hline & Privatisation & $\begin{array}{l}\text { Increases stress through increased } \\
\text { job insecurity }\end{array}$ & negative & critically low (1) \\
\hline \multirow[t]{4}{*}{ Neighbourhood } & $\begin{array}{l}\text { Mixed income housing in low } \\
\text { income neighbourhoods }\end{array}$ & $\begin{array}{l}\text { Positive impacts on MH through } \\
\text { improvement in neighbourhood } \\
\text { physical and social conditions; } \\
\text { negative impacts through disruptions } \\
\text { of social ties and social deterioration } \\
\text { in receiving neighbourhoods. }\end{array}$ & insufficient evidence & critically low (1) \\
\hline & Tenant based rental assistance & As above & inconclusive but suggestive positive & critically low (1) \\
\hline & $\begin{array}{l}\text { Warmth related housing } \\
\text { improvements }\end{array}$ & $\begin{array}{l}\text { Inhibiting a key intermediary } \\
\text { between poverty and poor health. } \\
\text { Qualitative data revealed links via } \\
\text { increased thermal comfort, increased } \\
\text { space, reduced noise and increased } \\
\text { housing satisfaction. }\end{array}$ & positive & moderate (1) \\
\hline & Physical housing improvements - & As above & mixed & moderate (1) \\
\hline
\end{tabular}


Table 2 Overview of intervention effects and pathways (Continued)

\begin{tabular}{|c|c|c|c|c|}
\hline Domain & Intervention & $\begin{array}{l}\text { Mechanistic pathway (as stated in } \\
\text { review) }\end{array}$ & $\begin{array}{l}\text { Overall evidence on MH } \\
\text { outcomes (positive effect, } \\
\text { negative effect, no effect, } \\
\text { inconclusive, mixed effect, } \\
\text { suggestive but inconclusive, } \\
\text { insufficient evidence) }\end{array}$ & $\begin{array}{l}\text { Strength of } \\
\text { Evidence: } \\
\text { AMSTAR } 2 \\
\text { grading } \\
\text { (number of } \\
\text { reviews) }\end{array}$ \\
\hline & $\begin{array}{l}\text { from slums, housing led } \\
\text { neighbourhood renewal }\end{array}$ & & & \\
\hline Environment & $\begin{array}{l}\text { Entry and integration policies for } \\
\text { migrants to high income countries }\end{array}$ & $\begin{array}{l}\text { Exclusionist contexts were worse for } \\
\text { mental health than assimilationist } \\
\text { (where migrants are afforded } \\
\text { citizenship but encouraged to } \\
\text { conform with host society norms) } \\
\text { and the best levels of mental health } \\
\text { were associated with integrationist } \\
\text { contexts (where migrants } \\
\text { are accepted in and afforded rights } \\
\text { within the new community.) }\end{array}$ & negative & low (1) \\
\hline \multirow[t]{6}{*}{ Social/Cultural } & $\begin{array}{l}\text { Family interventions (inc parenting } \\
\text { programmes) }\end{array}$ & $\begin{array}{l}\text { Behavioural problems are likely to } \\
\text { lead to secondary mental health } \\
\text { problems, such as depression }\end{array}$ & positive & critically low (1) \\
\hline & $\begin{array}{l}\text { Restriction of access to lethal } \\
\text { means }\end{array}$ & $\begin{array}{l}\text { Restriction of access prevents } \\
\text { successful completion of suicide but } \\
\text { not mental distress }\end{array}$ & positive & critically low (3) \\
\hline & School based MH education & $\begin{array}{l}\text { Education and awareness among } \\
\text { patients and/or physicians, leading to } \\
\text { increasing appropriate anti- } \\
\text { depressant prescribing, lower rates of } \\
\text { untreated major depression and } \\
\text { lower suicide }\end{array}$ & positive & critically low (1) \\
\hline & Gatekeeper education & As above & positive & critically low (1) \\
\hline & Screening & $\begin{array}{l}\text { Increased identification and } \\
\text { treatment of MH problems }\end{array}$ & insufficient evidence & critically low (1) \\
\hline & Mass media campaigns & $\begin{array}{l}\text { To change behaviour by affecting } \\
\text { decision-making processes at the in- } \\
\text { dividual level through message pro- } \\
\text { motion, potentially before crisis } \\
\text { occurs. }\end{array}$ & no effect & critically low (1) \\
\hline
\end{tabular}

[66], is important to ensure benefits of neighbourhood level interventions are maintained when delivered at scale.

Whilst the quality of Kato et al's [63] review was critically low; the existing extensive evidence base on local parenting interventions and the impact of parenting on mental health [67] supports the case for scaled up community parenting intervention.

The WHO recommends nations should have suicide prevention policies in place [3]. This review supports the use of tailored approaches to means restriction and multilevel awareness and education campaigns; but does not find convincing evidence on use of screening or standalone mass media campaigns.

The WHO European health equity framework [68] also highlights income security and social protection; decent living conditions; social and human capital and decent work and employment conditions as key areas of action. To inform national mental health policies, policy makers require research that evaluates the impacts of strategies that address the social determinants and factors that affect their implementation [69]. In regard to mental health and wellbeing inequity, this review finds limited evidence of how to achieve this; with some evidence supporting effective social protection and gender/ family policy. The lack of evidence may not only be due to the absence of policy, but also the inadequate funding to implement or evaluate the relevant policies that do exist. This review confirms this research gap and the need for further natural experiments and evaluations of non-health policies that address the social determinants of mental health.

Finally, there is a case to align approaches to tackling social determinants of mental and physical health, given 


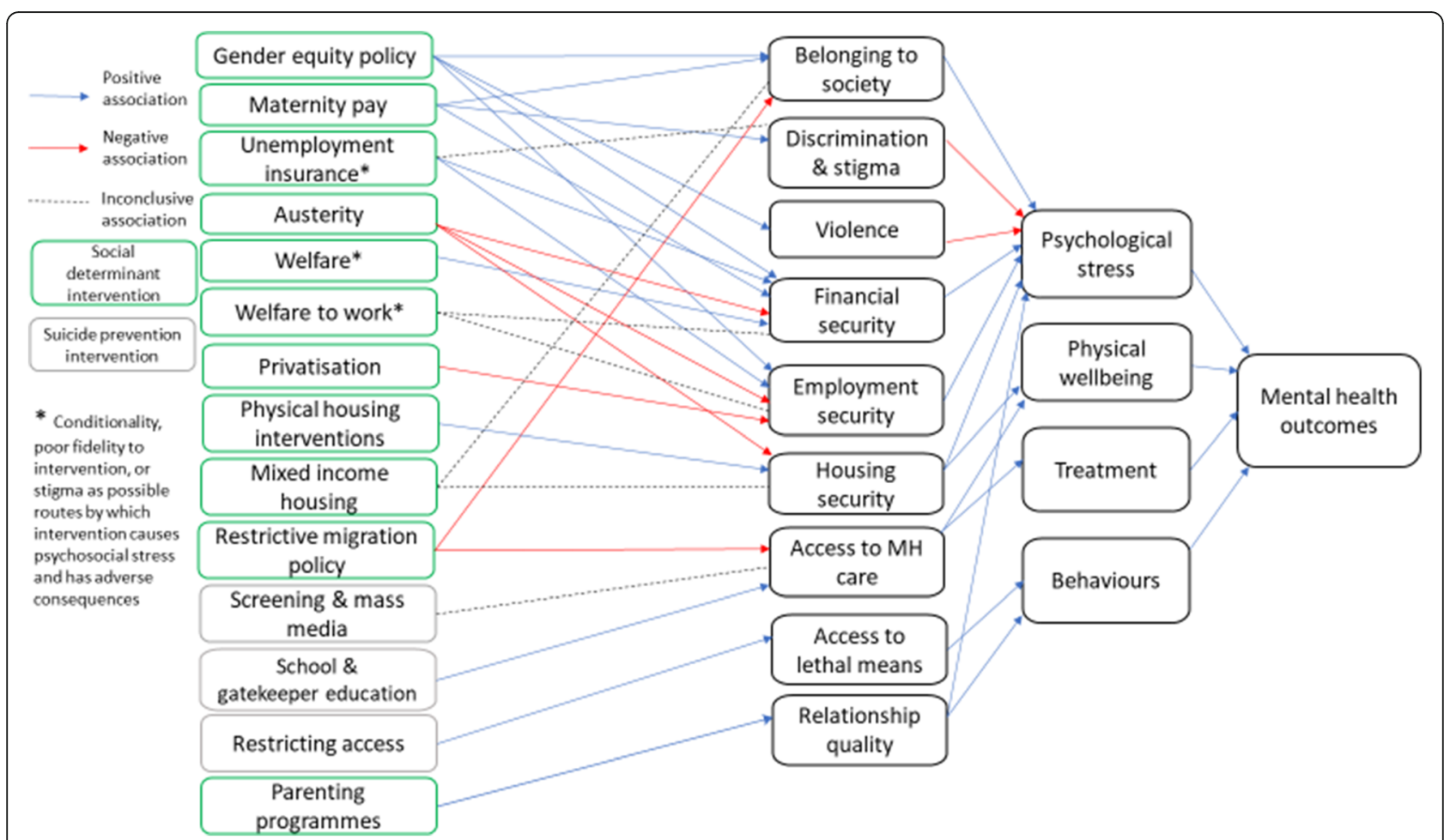

Fig. 2 Overview of mechanistic pathways for interventions as proposed by authors of included reviews

recent literature detailing psychosocial pathways by which social determinants impact on both physical and mental health [70]. Bambra et al. [35], looking at social determinants of health overall, without specifying population level delivery, found evidence of impact across both physical and mental health across rental assistance programmes so that low income families can choose where to live; improving environmental housing interventions; employment changes that affected shift patterns, and job control or security. We did not map against combined mechanistic pathways for physical and mental health, but this could be a useful focus for research going forward.

\section{Limitations of review}

Our focus on national/population level interventions, may have excluded relevant interventions occurring at lower than national level. Future reviews should focus on local or community level interventions which address social determinants of mental health with potential to scale at population level.

While we used a recognised tool to assess quality of reviews, the AMSTAR 2 may not be most appropriate for complex public health interventions. Review tools such as the AMSTAR 2, developed in relation to healthcare research, are conceptually framed and weighted towards a hierarchy of evidence that prefers RCT and meta-analytic synthesis and assumes that they are possible. A rigorous and well considered public heath systematic review that contains different forms of evidence may struggle to score highly on this criterion.

Refining the search to systematic review level evidence only, may also have missed individual studies with good evidence that have not yet been synthesized at review level. We relied on variable methods used in the included systematic reviews for appraisal of quality and synthesis of primary studies.

There are methodological challenges associated with evaluating social interventions delivered at population scale and which can be distal to the mental health outcome, forming complex pathways to impact.

Methods employed in primary research studies limit the strength of findings. Quasi-experimental and observational studies have limited power to explain causality but were commonly used; likely due to the scale of intervention, population of interest, ethical considerations, policy governance (the extent to which researchers are able to influence it or speed and scale of implementation) or availability of data. Bias was introduced in many studies by sub-optimal measurement (such as reliance upon retrospective self report) of mental health and 
intervention related factors, and not including all relevant populations in the dataset.

To enhance the strength of future review level findings, primary evaluations of mental health policies and interventions should be planned in advance, before implementation of new policies/interventions, to include robust measurement of mental health status longitudinally with samples that are representative of diverse populations. Where experimental designs are not employed, observational studies can employ analytical methods designed to overcome methodological limitations. One approach is to create control groups within one population dataset, for instance employing a differencein-differences analysis to compare impacts of policies on different subgroups of the population [71]. Another approach is to measure potential confounders and adjust for them in analysis through methods such as stratification, matching, or standardization.

Fidelity is difficult to achieve as most of these interventions are implemented in varied and broad contexts, and are influenced during implementation by multiple contextual factors, many of which are not easily measured. A key example of implementation related factors is the conditionality of welfare interventions (an aspect of implementation rather than core component of the intervention) as potentially mitigating mental health benefits of increased income [48]. Renahy et al. [49] also found variability in mental health impacts of unemployment insurance, suggesting societal stigma as a relevant contextual factor. The majority of included reviews discussed possible impacts of context and implementation but did not directly evaluate this at review level.

Authors of included reviews highlighted that future studies should take implementation and contextual factors into account during design and analysis to enable more comprehensive evaluation. This could include a priori identification of likely relevant implementation or contextual factors which can be collected and subsequent sub-group, sensitivity or effect mediation/moderation/interaction analyses carried out as appropriate. Other methodologies can enable investigation of context-related clustering without measuring factors directly. Multilevel analyses of cross sectional or longitudinal data allow measurement of change across individuals and the wider social contexts in which they live, including analysis of cross level interactions and associations, and variation of effect for target population and the wider population [72]. In ecological studies, adjustment for time and country specific effects can be made [73]. At review level, realist approaches should be considered to better draw out population and context related factors which affect effectiveness of policies or interventions [74].

Clarity on mechanistic pathways can help understand how these interventions work most effectively and what is needed to support this in implementation, but evaluation designs often do not incorporate this. None of the included reviews collected outcomes at points along the proposed mechanistic pathway, and it is unclear if this was done in primary evaluations. The mechanistic pathways set out in Fig. 2 can act as a starting point for developing causal frameworks for more comprehensive testing and evaluation of future interventions. Complex system approaches and associated frameworks provide routes to better integrate evidence related to intervention, mechanism and context [75].

\section{Conclusion}

This umbrella review has identified a small and overall low quality evidence base for national level interventions addressing the social determinants of mental health.

The most robust evidence base centred on welfare and employment support, which national policymakers should consider for implementation. Other national level interventions that are indicated in this review for policy consideration are gender equity policy, less restrictive migration policy, restricting means/ multi-component campaigns for preventing suicide and at scale delivery of community parenting interventions.

There is a need for better quality primary research and improved reporting in systematic reviews that focus on impacts of conditional benefits, neighbourhood renewal or mixed income housing on mental health. No systematic review level evidence was found relating to national strategies for violence reduction, addressing environmental hazards, community services, age and ethnicity inclusive policies and their impact on mental health. There is a wider evidence base of locally evaluated interventions that may be scaled but it is important for these to be evaluated to assess effectiveness when implemented at national/population level.

\section{Supplementary Information}

The online version contains supplementary material available at https://doi. org/10.1186/s12889-021-12145-1.

Additional file 1. Search strategy used in OVID Medline

Additional file 2. AMSTAR 2 checklist tool.

Additional file 3. Data extraction tool

Additional file 4. Excluded studies at full text screening stage (with reason)

Additional file 5. Summary table of included studies.

\section{Acknowledgments}

Not applicable.

Authors' contributions

IW, JS, and YN conceived of the study. NPS undertook the literature search. IW, KOH, NS, YN, SR, CC, TT, MB extracted data. NS and IW led drafting of the manuscript and all authors reviewed and edited the final manuscript. All authors have approved the final manuscript before submission. 


\section{Funding}

No specific funding sources were available for this study. CC was funded through the NIHR ARC Yorkshire and Humber (NIHR200166). MB is funded though NIHR doctoral fellowship (NIHR300689). TT is funded by an academic clinical lectureship from the UK NIHR. Salaries for other authors were paid by respective employers. The views expressed in this publication are those of the author(s) and not necessarily those of the National Institute for Health Research or the Department of Health and Social Care.

\section{Availability of data and materials}

The datasets generated and/or analysed during the current study are available from the corresponding author on reasonable request.

\section{Declarations}

\section{Ethics approval and consent to participate}

Not applicable - secondary analysis of published data only.

\section{Consent for publication}

Not applicable - secondary analysis of published data only.

\section{Competing interests}

NS, IW, JS, KOH, TT and NPS are currently employed or affiliated with Public Health England. YN, SR, TT MB and CC do not declare any competing interests.

\section{Author details}

${ }^{1}$ City University London, Northampton Square, EC1V OHB, London, UK. ${ }^{2}$ Hull York Medical School, University of York, Heslington, York YO10 5DD, England. ${ }^{3}$ Leeds Teaching Hospitals NHS Trust, Great St George Street, Leeds LS1 3EX, England. ${ }^{4}$ School of Health and Related Research, The University of Sheffield, Regent Court, 30 Regent, Sheffield S1 4DA, England. ${ }^{5}$ Department of Health Services Research and Policy, The London School of Hygiene and Tropical Medicine, London WC1E 7H, UK. ${ }^{6}$ Public Health England, Wellington House, 133-155 Waterloo Road, London SE1 8UG, UK. ${ }^{7}$ Bradford Institute for Health Research, Bradford Royal Infirmary, Bradford Teaching Hospitals NHS Foundation Trust, Duckworth Lane, Bradford BD9 6RJ, England. ${ }^{8}$ Centre for Global Non-Communicable Disease, Institute for Global Health, UCL, 30 Guilford, London WC1N 1EH, UK. ${ }^{9}$ School of Health and Community Studies, Leeds Beckett University, Portland Building, PD519, Portland Place, Leeds LS1 $3 \mathrm{HE}, \mathrm{UK}$.

\section{Received: 22 April 2021 Accepted: 15 September 2021}

Published online: 18 November 2021

\section{References}

1. Eaton J, McCay L, Semrau M, Chatterjee S, Baingana F, Araya R, et al. Scale up of services for mental health in low-income and middle-income countries. Lancet. 2011;378(9802):1592-603. https://doi.org/10.1016/S01406736(11)60891-X.

2. Patel $\mathrm{V}$, et al. Reducing the treatment gap for mental disorders: a WPA survey. World Psychiatry. 2010;9(3):169-76. https://doi.org/10.1002/j.2051-554 5.2010.tb00305.x.

3. World Health Organization, Mental health action plan 2013-2020. Geneva: WHO. 2013. Available at: https://www.who.int/publications/i/item/ 9789241506021

4. World Health Organization. World health statistics 2016: monitoring health for the SDGs sustainable development goals. Geneva: World Health Organization; 2016.

5. Patel V, Saxena S, Lund C, Thornicroft G, Baingana F, Bolton P, et al. The lancet commission on global mental health and sustainable development. Lancet. 2018; 392(10157):1553-98. https:/doi.org/10.1016/S0140-6736(18)31612-X.

6. Lund C, Breen A, Flisher AJ, Kakuma R, Corrigall J, Joska JA, et al. Poverty and common mental disorders in low and middle income countries: a systematic review. Soc Sci Med. 2010;71(3):517-28. https://doi.org/10.1016/j. socscimed.2010.04.027.

7. Reiss F. Socioeconomic inequalities and mental health problems in children and adolescents: a systematic review. Soc Sci Med. 2013;90:24-31. https:// doi.org/10.1016/j.socscimed.2013.04.026.

8. Harvey SB, Modini M, Joyce S, Milligan-Saville JS, Tan L, Mykletun A, et al. Can work make you mentally ill? A systematic meta-review of work-related risk factors for common mental health problems. Occup Environ Med. 2017; 74(4):301-10. https://doi.org/10.1136/oemed-2016-104015.

9. Madsen IEH, Nyberg ST, Magnusson Hanson LL, Ferrie JE, Ahola K, Alfredsson L, et al. Job strain as a risk factor for clinical depression: systematic review and meta-analysis with additional individual participant data. Psychol Med. 2017;47(8):1342-56. https:/ doi.org/10.1017/5003329171600355X.

10. Milner A, Page A, LaMontagne AD. Cause and effect in studies on unemployment, mental health and suicide: a meta-analytic and conceptual review. Psychol Med. 2014;44(5):909-17. https://doi.org/10.1017/S0033291 713001621.

11. van der Noordt M, IJzelenberg H, Droomers M, Proper KI. Health effects of employment: a systematic review of prospective studies. Occup Environ Med. 2014;71(10):730-6. https://doi.org/10.1136/oemed-2013-101891.

12. Naik Y, Baker P, Ismail SA, Tillmann T, Bash K, Quantz D, et al. Going upstream - an umbrella review of the macroeconomic determinants of health and health inequalities. BMC Public Health. 2019;19(1):1678. https:// doi.org/10.1186/s12889-019-7895-6.

13. Stuckler D, Basu S, Suhrcke M, Coutts A, McKee M. The public health effect of economic crises and alternative policy responses in Europe: an empirical analysis. Lancet. 2009;374(9686):315-23. https://doi.org/10.1016/S0140-673 6(09)61124-7.

14. Harris, J, et al., Health, mental health and housing conditions in England. 2010.

15. Kyle T, Dunn JR. Effects of housing circumstances on health, quality of life and healthcare use for people with severe mental illness: a review. Health Soc Care Community. 2008;16(1):1-15. https://doi.org/10.1111/j.1365-2524.2 007.00723.x

16. Nelson $G$, Aubry T, Lafrance A. A review of the literature on the effectiveness of housing and support, assertive community treatment, and intensive case management interventions for persons with mental illness who have been homeless. Am J Orthop. 2007;77(3):350-61. https://doi.org/1 0.1037/0002-9432.77.3.350.

17. Chu PS, et al. Meta-analysis of the relationships between social support and well-being in children and adolescents. J Soc Clin Psychol. 2010;29(6):62445. https://doi.org/10.1521/jscp.2010.29.6.624.

18. Elgar FJ, Davis CG, Wohl MJ, Trites SJ, Zelenski JM, Martin MS. Social capital, health and life satisfaction in 50 countries. Health Place. 2011;17(5):1044-53. https://doi.org/10.1016/j.healthplace.2011.06.010.

19. Leigh-Hunt N, Bagguley D, Bash K, Turner V, Turnbull S, Valtorta N, et al. An overview of systematic reviews on the public health consequences of social isolation and loneliness. Public Health. 2017;152:157-71. https://doi.org/10.1 016/j.puhe.2017.07.035.

20. Nyqvist F, Forsman AK, Giuntoli G, Cattan M. Social capital as a resource for mental well-being in older people: a systematic review. Aging Ment Health. 2013;17(4):394-410. https://doi.org/10.1080/13607863.2012.742490.

21. Lorenc T, Clayton S, Neary D, Whitehead M, Petticrew M, Thomson H, et al. Crime, fear of crime, environment, and mental health and wellbeing: mapping review of theories and causal pathways. Health Place. 2012;18(4): 757-65. https://doi.org/10.1016/j.healthplace.2012.04.001.

22. Fowler PJ, Tompsett CJ, Braciszewski JM, Jacques-Tiura AJ, Baltes BB. Community violence: a meta-analysis on the effect of exposure and mental health outcomes of children and adolescents. Dev Psychopathol. 2009;21(1): 227-59. https://doi.org/10.1017/S0954579409000145.

23. McDonald CC, Richmond TR. The relationship between community violence exposure and mental health symptoms in urban adolescents. J Psychiatr Ment Health Nurs. 2008;15(10):833-49. https://doi.org/10.1111/j.1365-2850.2 008.01321.x.

24. Satyanarayana VA, Chandra PS, Vaddiparti K. Mental health consequences of violence against women and girls. Curr Opin Psychiatry. 2015;28(5):350-6. https://doi.org/10.1097/YCO.0000000000000182.

25. Bücker $\mathrm{S}$, et al. Subjective well-being and academic achievement: A metaanalysis. J Res Pers. 2018;74:83-94. https://doi.org/10.1016/j.jpp.2018.02.007.

26. Chang-Quan H, Zheng-Rong W, Yong-Hong L, Yi-Zhou X, Qing-Xiu L. Education and risk for late life depression: a meta-analysis of published literature. Int J Psychiatry Med. 2010;40(1):109-24. https://doi.org/10.2190/ PM.40.1.i.

27. Esch P, Bocquet V, Pull C, Couffignal S, Lehnert $T$, Graas $M$, et al. The downward spiral of mental disorders and educational attainment: a systematic review on early school leaving. BMC Psychiatry. 2014;14(1):237. https://doi.org/10.1186/s12888-014-0237-4.

28. Stuckler D, et al. Austerity and health: the impact in the UK and Europe. Eur J Public Health. 2017;27(suppl_4):18-21. 
29. Wickham S, Bentley L, Rose T, Whitehead M, Taylor-Robinson D, Barr B. Effects on mental health of a UK welfare reform, universal credit: a longitudinal controlled study. Lancet Public Health. 2020;5(3):e157-64. https://doi.org/10.1016/\$2468-2667(20)30026-8.

30. Van den Berg $M$, et al. Health benefits of green spaces in the living environment: A systematic review of epidemiological studies. Urban For Urban Green. 2015;14(4):806-16. https://doi.org/10.1016/j.ufug.2015.07.008.

31. van den Bosch $M$, Ode Sang $\AA$. Urban natural environments as naturebased solutions for improved public health - a systematic review of reviews. Environ Res. 2017;158:373-84. https://doi.org/10.1016/j.envres.2017.05.040.

32. Lund C, Brooke-Sumner C, Baingana F, Baron EC, Breuer E, Chandra P, et al. Social determinants of mental disorders and the sustainable development goals: a systematic review of reviews. Lancet Psychiatry. 2018;5(4):357-69. https://doi.org/10.1016/S2215-0366(18)30060-9.

33. Arango C, Díaz-Caneja CM, McGorry PD, Rapoport J, Sommer IE, Vorstman JA, et al. Preventive strategies for mental health. Lancet Psychiatry. 2018;5(7): 591-604. https://doi.org/10.1016/S2215-0366(18)30057-9.

34. Alegría M, NeMoyer A, Falgàs Bagué I, Wang Y, Alvarez K. Social determinants of mental health: where we are and where we need to go. Curr Psychiatry Rep. 2018; 20(11):95. https://doi.org/10.1007/s11920-018-0969-9.

35. Bambra C, Gibson M, Sowden A, Wright K, Whitehead M, Petticrew M. Tackling the wider social determinants of health and health inequalities: evidence from systematic reviews. J Epidemiol Community Health. 2010; 64(4):284-91. https://doi.org/10.1136/jech.2008.082743.

36. Higgins JP, et al. Cochrane handbook for systematic reviews of interventions. London: John Wiley \& Sons; 2019.

37. U.S. National Library of Medicine, Database of abstracts of reviews of effects (DARE). 2016. [online document] Available at https://www.ncbi.nlm.nih.gov/ pubmedhealth/about/DARE/

38. World Health Organization and Calouste Gulbenkian Foundation. Social determinants of mental health. Geneva: World Health Organisation; 2014.

39. Thompson Reuters. EndNote X9 reference management software. 2018. [online] Available at: http://endnote.com/product-details.

40. Shea BJ, Reeves BC, Wells G, Thuku M, Hamel C, Moran J, et al. AMSTAR 2: a critical appraisal tool for systematic reviews that include randomised or non-randomised studies of healthcare interventions, or both. Bmj. 2017;358: j4008. https://doi.org/10.1136/bmj.j4008.

41. Aitken Z, Garrett CC, Hewitt B, Keogh L, Hocking JS, Kavanagh AM. The maternal health outcomes of paid maternity leave: a systematic review. Soc Sci Med. 2015;130:32-41. https://doi.org/10.1016/j.socscimed.2015.02.001.

42. Borrell C, Palencia L, Muntaner C, Urquia M, Malmusi D, O'Campo P. Influence of macrosocial policies on women's health and gender inequalities in health. Epidemiol Rev. 2014;36(1):31-48. https://doi.org/10.1 093/epirev/mxt002.

43. Staehelin K, Bertea PC, Stutz EZ. Length of maternity leave and health of mother and child--a review. Int J Public Health. 2007;52(4):202-9. https://doi. org/10.1007/s00038-007-5122-1.

44. McLaughlin KA, Xuan Z, Subramanian SV, Koenen KC. State-level women's status and psychiatric disorders among US women. Soc Psychiatry Psychiatr Epidemiol. 2011;46(11):1161-71. https://doi.org/10.1007/s00127-010-0286-z.

45. McAllister A, Fritzell S, Almroth M, Harber-Aschan L, Larsson S, Burström B. How do macro-level structural determinants affect inequalities in mental health? - a systematic review of the literature. Int J Equity Health. 2018;17(1): 180. https://doi.org/10.1186/s12939-018-0879-9.

46. Gibson M, Thomson H, Banas K, Lutje V, McKee MJ, Martin SP, et al. Welfareto-work interventions and their effects on the mental and physical health of lone parents and their children. Cochrane Database Syst Rev. 2017; Issue 2. Art. No.: CD009820. https://doi.org/10.1002/14651858.CD009820.pub2

47. Pega $F$, et al. In-work tax credits for families and their impact on health status in adults. Cochrane Database Syst Rev. 2013. Issue 8. Art. No.: CD009963. https://doi.org/10.1002/14651858.CD009963.pub2.

48. Lucas PJ, McIntosh K, Petticrew M, Roberts HM, Shiell A. Financial benefits for child health and well-being in low income or socially disadvantaged families in developed world countries. Campbell Syst Rev. 2008;4(1):1-93. https://doi.org/10.4073/csr.2008.9.

49. Renahy E, Mitchell C, Molnar A, Muntaner C, Ng E, Ali F, et al. Connections between unemployment insurance, poverty and health: a systematic review. Eur J Public Health. 2018;28(2):269-75. https://doi.org/10.1093/eurpub/ckx235.

50. O'Campo P, Molnar A, Ng E, Renahy E, Mitchell C, Shankardass K, et al. Social welfare matters: a realist review of when, how, and why unemployment insurance impacts poverty and health. Soc Sci Med. 2015; 132:88-94. https://doi.org/10.1016/j.socscimed.2015.03.025.

51. Puig-Barrachina V, Malmusi D, Martínez JM, Benach J. Monitoring social determinants of health inequalities: the impact of unemployment among vulnerable groups. Int J Health Serv. 2011;41(3):459-82. https://doi.org/10.21 90/HS.41.3.d.

52. Egan M, Petticrew M, Ogilvie D, Hamilton V, Drever F. "profits before people"? A systematic review of the health and safety impacts of privatising public utilities and industries in developed countries. J Epidemiol Community Health. 2007;61(10):862-70. https://doi.org/10.1136/jech.2006.053231.

53. Anderson LM, St. Charles J, Fullilove MT, Scrimshaw SC, Fielding JE, Normand J. Providing affordable family housing and reducing residential segregation by income. Am J Prev Med. 2003;24(3):47-67. https://doi.org/1 0.1016/S0749-3797(02)00656-6.

54. Thomson H, Thomas S, Sellstrom E, Petticrew M, Cochrane Public Health Group. Housing improvements for health and associated socio-economic outcomes. Cochrane Database Syst Rev. 2013;2:CD008657. https://doi.org/1 0.1002/14651858.CD008657.pub2.

55. Juárez SP, Honkaniemi H, Dunlavy AC, Aldridge RW, Barreto ML, Katikireddi SV, et al. Effects of non-health-targeted policies on migrant health: a systematic review and meta-analysis. Lancet Glob Health. 2019;7(4):e420-35. https://doi.org/10.1016/S2214-109X(18)30560-6.

56. Meuleman B, Reeskens T. The relation between integration policy and majority attitudes toward immigration: An Empirical Test Across European Countries. In Proceedings of the International Society of Political Psychology conference: 9-12 July 2008; Paris. Lirius: ISPP

57. Gunnell D, Knipe D, Chang SS, Pearson M, Konradsen F, Lee WJ, et al. Prevention of suicide with regulations aimed at restricting access to highly hazardous pesticides: a systematic review of the international evidence. Lancet Glob Health. 2017;5(10):e1026-37. https://doi.org/10.1016/S2214-1 09X(17)30299-1.

58. Torok M, Calear A, Shand F, Christensen H. A systematic review of mass media campaigns for suicide prevention: understanding their efficacy and the mechanisms needed for successful behavioral and literacy change. Suicide Life Threat Behav. 2017;47(6):672-87. https://doi.org/10.1111/ sltb. 12324.

59. Zechmeister I, et al. Is it worth investing in mental health promotion and prevention of mental illness. A Syst Rev Evid Econ Evaluations BMC Public Health. 2008;8:20.

60. Mann JJ, Apter A, Bertolote J, Beautrais A, Currier D, Haas A, et al. Suicide prevention strategies: a systematic review. Jama. 2005;294(16):2064-74. https://doi.org/10.1001/jama.294.16.2064.

61. Zalsman G, Hawton K, Wasserman D, van Heeringen K, Arensman E, Sarchiapone $M$, et al. Suicide prevention strategies revisited: 10-year systematic review. Lancet Psychiatry. 2016;3(7):646-59. https://doi.org/10.101 6/S2215-0366(16)30030-X.

62. Lynch, RG, Exceptional returns: Economic, fiscal, and social benefits of investment in early childhood development. 2004. Washington DC: Economic Policy Institute.

63. Kato N, Yanagawa T, Fujiwara T, Morawska A. Prevalence of Children's mental health problems and the effectiveness of population-level family interventions. J Epidemiol. 2015;25(8):507-16. https://doi.org/10.2188/jea.JE2 0140198.

64. World Health Organization and Calouste Gulbenkian Foundation. Social determinants of mental health. Geneva: World Health Organization. 2014.

65. Allen J, Balfour R, Bell R, Marmot M. Social determinants of mental health. Int Rev Psychiatry. 2014;26(4):392-407. https://doi.org/10.3109/09540261.2 014.928270.

66. Milat AJ, Bauman A, Redman S. Narrative review of models and success factors for scaling up public health interventions. Implement Sci. 2015;10(1): 113. https://doi.org/10.1186/s13012-015-0301-6.

67. Barlow J, Coren E. The effectiveness of parenting programs: a review of Campbell reviews. Res Soc Work Pract. 2017;28(1):99-102. https://doi.org/1 $0.1177 / 1049731517725184$.

68. World Health Organization European Regional Office. Healthy, prosperous lives for all: the European health equity status report (2019). Copenhagen: WHO EURO; 2019.

69. Haro JM, Ayuso-Mateos JL, Bitter I, Demotes-Mainard J, Leboyer M, Lewis SW, et al. ROAMER: roadmap for mental health research in Europe. Int J Methods Psychiatr Res. 2014;23(S1):1-14. https://doi.org/10.1002/mpr.1406. 
70. Stansfield J, Bell R. Applying a psychosocial pathways model to improving mental health and reducing health inequalities: practical approaches. Int I Soc Psychiatry. 2019;65(2):107-13. https://doi.org/10.1177/0020764018823816.

71. Stearns J. The long-run effects of wage replacement and job protection: evidence from two maternity leave reforms in Great Britain. 2018. Colchester: Institute for Social and Economic Research. [online] Available at: https://www.iser.essex.ac.uk/research/publications/525235

72. Chen Y-Y, Subramanian SV, Acevedo-Garcia D, Kawachi I. Women's status and depressive symptoms: a multilevel analysis. Soc Sci Med. 2005;60(1):4960. https://doi.org/10.1016/j.socscimed.2004.04.030.

73. Winegarden CR, Bracy PM. Demographic consequences of maternal-leave programs in industrial countries: evidence from fixed-effects models. South Econ J. 1995:1020-35.

74. Pawson $\mathrm{R}$, et al. Realist review-a new method of systematic review designed for complex policy interventions. J Health Serv Res Policy. 2005;10(1_suppl):21-34

75. McGill E, Er V, Penney T, Egan M, White M, Meier P, et al. Evaluation of public health interventions from a complex systems perspective: a research methods review. Soc Sci Med. 2021;272:113697. https://doi.org/10.1016/j. socscimed.2021.113697.

\section{Publisher's Note}

Springer Nature remains neutral with regard to jurisdictional claims in published maps and institutional affiliations.

Ready to submit your research? Choose BMC and benefit from:

- fast, convenient online submission

- thorough peer review by experienced researchers in your field

- rapid publication on acceptance

- support for research data, including large and complex data types

- gold Open Access which fosters wider collaboration and increased citations

- maximum visibility for your research: over $100 \mathrm{M}$ website views per year

At $\mathrm{BMC}$, research is always in progress.

Learn more biomedcentral.com/submissions 